http://jmscr.igmpublication.org/home/

ISSN (e)-2347-176x ISSN (p) 2455-0450

crossref DOI: https://dx.doi.org/10.18535/jmscr/v7i12.143

Journal Of Medical Science And Clinical Research

\title{
Anterior transposition of ulnar nerve for cubital tunnel syndrome and use of FCU aponeurotic sling
}

\author{
Authors \\ Dr Prince.H.P ${ }^{1}$, Prof. J. Jaganmohan, MS, $\mathrm{MCh}^{2 *}$, Dr T.M. Balakrishnan, MS, $\mathrm{MCh}^{3}$ \\ ${ }^{1}$ Resident, Department of Plastic, Reconstructive and Facio-Maxillary Surgery, Madras Medical College, \\ Chennai-3 \\ ${ }^{2}$ Prof \& Head of department, Department of Plastic, Reconstructive and Facio-Maxillary Surgery, Madras \\ Medical College, Chennai-3 \\ ${ }^{3}$ Assistant professor, Department of Plastic, Reconstructive and Facio-Maxillary Surgery, Madras Medical \\ College, Chennai-3 \\ *Corresponding Author
}

Prof. J. Jaganmohan, MS, MCh

Prof \& Head of department, Department of Plastic, Reconstructive and Facio-Maxillary Surgery, Madras

Medical College, Chennai-3, India

Abstract
Objective: To evaluate the results of subcutaneous anterior transposition of the ulnar nerve in the
surgical management of cubital tunnel syndrome and to use FCU aponeurotic fascia to retain the
position of anteriorly transposed ulnar nerve.
Methods: This is a retrospective study, which evaluated 15 patients (5 males, 10 females; mean age: 48
years; range: 26 to 60 years) who underwent subcutaneous transposition of the ulnar nerve. Mean
follow-up period was 2 years (range: 1 year 2 months to 2 years 6 months). Modified McGowan's
classification was used for preoperative scoring and the Wilson \& Krout classification for postoperative
clinical evaluation. Preoperatively 2 patients (13\%) had Grade $1,3(20 \%)$ had Grade $2 A, 4(27 \%)$ had
Grade 2 B, and 6 (40\%) had Grade 3 neuropathy.
Results: There were excellent results in 10 patients (66\%), good in $4(26 \%)$ and fair in 1patient $(7 \%)$.
There was a negative correlation between the preoperative McGowan grade and the postoperative
Wilson \& Krout score (p<0.05). The success rate of the operation was significantly lower in patient
groups as the time from symptom onset increased (p<0.05). There were no complications.
Conclusion: Subcutaneous anterior transposition of the ulnar nerve is an effective and reliable surgical
method with a low complication rate for the treatment of cubital tunnel syndrome.
Keywords: Anterior transposition; cubital tunnel syndrome; neuropathy; ulnar nerve.

\section{Introduction}

Cubital tunnel is an osteofibrous tunnel in the elbow, posterior to the medial epicondyle of humerus, through which ulnar nerve passes from the extensor aspect of arm to the flexor aspect of forearm.
Cubital tunnel syndrome is an entrapment neuropathy of ulnar nerve at elbow joint. it is the second most common entrapment neuropathy following carpal tunnel syndrome ${ }^{[1-5]}$.

The following structures cause compression in this region 
1. The arcade of struthers- a tendinous band extending between the medial intermuscular septum and the medial head of tricesps.

2. Osborne's fascia- the fascia between the two heads of FCU.

3. Deep flexor aponeurosis - between the FCU and FDS to the FDP about $5 \mathrm{~cm}$ distal to medial epicondyle.

4. The cubital tunnel can become narrow causing the bulging of ulnar collateral ligament in elbow flexion.

5. Epitrochleaanconeus- an anomalous muscle in the cubital tunnel, present in 20 percent of population causes compression .

Patients mostly present with numbness along ulnar nerve distribution. Patients also complaints of pain in the elbow, specially behind medial epicondyle, radiating to proximal forearm. On examination, intrinsic muscles weakness and reduced grip strength can be elicited. In severe and prolonged cases, significant atrophy of the intrinsics, especially the first dorsal interosseous muscle, may occur ${ }^{[7] \text {. }}$

Initially the patient will be treated conservatively with adequate rest and preventing elbow flexion and pressure on the nerve. Brace immobilisation is done for persistent cases.

Surgical management is indicated when non operative methods fail to relieve these symptoms ${ }^{[1,8]}$. Which includes simple decompression, simple decompression plus medial epicondylectomy, and anterior transposition (subcutaneous, intramuscular, submuscular routes). However, the superiority of a surgical technique is still controversial. Subcutaneous anterior transposition of the ulnar nerve is a common and relatively simple surgical procedure

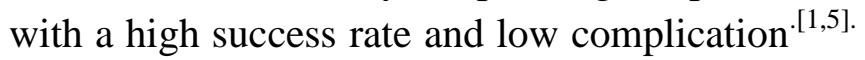
More often the transposed nerve rolls over the anterior aspect of medial epicondyle causing pain or discomfort and also becomes prone for injury.

In this study, we retrospectively analyzed the results of patients with cubital tunnel syndrome who underwent subcutaneous anterior transposition of the ulnar nerve. In all cases the position of nerve was retained by applying a FCU aponeurotic sling.

\section{Patients and Methods}

A retrospective analysis of fifteen patients who underwent subcutaneous anterior transposition for cubital tunnel syndrome was done. Study was done done on patients operated in our deparment during the 6months time interval between July 2017 and Jan 2018.

5 males, 10 females; mean age: 48 years; range: 26 to 60 years. The right side was involved in 9 patients and the left in 6. All operations were performed by a single surgeon.

The diagnosis of carpal tunnel syndrome was made on clinical findings and supported by electro-diagnostic studies. Clinical findings include, numbness and loss of sensation in the ulnar nerve distribution, pain over medial aspect of elbow, loss of fine motor skills, intrinsic muscle weakness and reduced grip strength, in particular atrophy of the first dorsal interosseous, a positive Tinel's sign at the elbow, a positive elbow flexion test.

Electrodiagnostic tests included nerve conduction studies and needle EMG. A motor conduction velocity (MCV) of less than $47 \mathrm{~m} / \mathrm{s}$ and a sensory conduction velocity (SCV) of less than $54 \mathrm{~m} / \mathrm{s}$ were considered as abnormal. Pathological findings on EMG included fibrillation activity, decreased recruitment, and abnormalities in the configuration of the motor unit action potential. ${ }^{[9]}$

All patients had undergone conservative management for a minimum of 3 months before surgery. Elbow radiographs were performed to rule out additional bone pathologies. All patients had idiopathic etiology.

Patients were classified into four grades according to the modified McGowan classification (Table 1). ${ }^{[10]}$

\section{Inclusion Criteria}

$$
\text { 1. Age }>18 \text { yrs. }
$$


2. Patients with clinical signs \& symptoms suggestive of CTS, supported by electro diagnostic tests.

3. Cooperative and oriented patients, who may come for regular follow up.

4. Patients with no improvement after 3 months of conservative management.

\section{Exclusion Criteria}

1. History of major trauma or prior surgery of elbow.

2. Evidence of generalised neuropathy, arthritis, long standing diabetes.

3. No significant changes in electro diagnostic studies.

\section{Surgical Technique}

All patients were operated under general anesthesia, under tourniquet control. A vertical incision $(12-15 \mathrm{~cm})$ is made along the course of ulnar nerve in the elbow midway between olecranon and medial epicondyle. Care was taken to avoid injury to medial cutaneous nerve of forearm. Ulnar nerve was identified posterior to medial epicondyle in ulnar groove. Ulnar nerve was well released both proximally and distally of any tendinous band, intramuscular septum or any factors causing compression or adherence. The motor branches of the nerve supplying FCU and FDP were preserved. The nerve was then carefully lifted from its bed using an umbilical tape. Neurolysis done, to dissect the posterior motor branches from the ulnar nerve, to allow adequate anterior transposition. It should be confirmed that nerve lies loosely with no proximal or distal compression. Nerve was then transposed anterior to the medial epicondyle in a subcutaneous plane. A distally based fascial flap was elevated anterior to the medical epicondyle on the of flexor carpi ulnaris aponeurosis of size 1- to 1.5-cm2 (Fig 1C). This fascial flap was looped around the nerve and distal end inset was given back to fascia itself forming a band that loops around the nerve to retain it in its anterior transposed position.
The elbow was moved through its full range to ensure good gliding of the ulnar nerve and to rule out any further compression of the nerve.

The elbow was immobilized for 10 days postoperatively and active range of motion exercises were started after that to allow excursion of the ulnar nerve and prevent fibrosis in the surgical bed.

The pain at the medial epicondyle was found to be relieved on post op day one in all cases. No complications were observed.

Results were evaluated with the modified Wilson \& Krout criteria (Table 2) ${ }^{[11]}$ Multi variant analysis using SPSS-21 was used in the statistical evaluation of the data. $\mathrm{P}$ values of less than 0.05 were considered statistically significant.

\section{Results}

The postoperative mean follow-up was 2 years. There were no early or late complications or recurrences.

Symptomatic improvement was obtained in all patients. Results based on the Wilson \& Krout classification were excellent in 10 patients (66\%), good in $4(26 \%)$ and fair in $1(7 \%)$ (Table 3$)$.

There was a negative correlation between the preoperative McGowan grade and the postoperative Wilson \& Krout score $(\mathrm{p}<0.05)$ (Table 3). The success rate of the operation was significantly lower in patient groups as the time from symptom onset increased $(\mathrm{p}<0.05)$ (Table 4). 


\section{JMSCR Vol||07||Issue||12||Page 808-816||December}

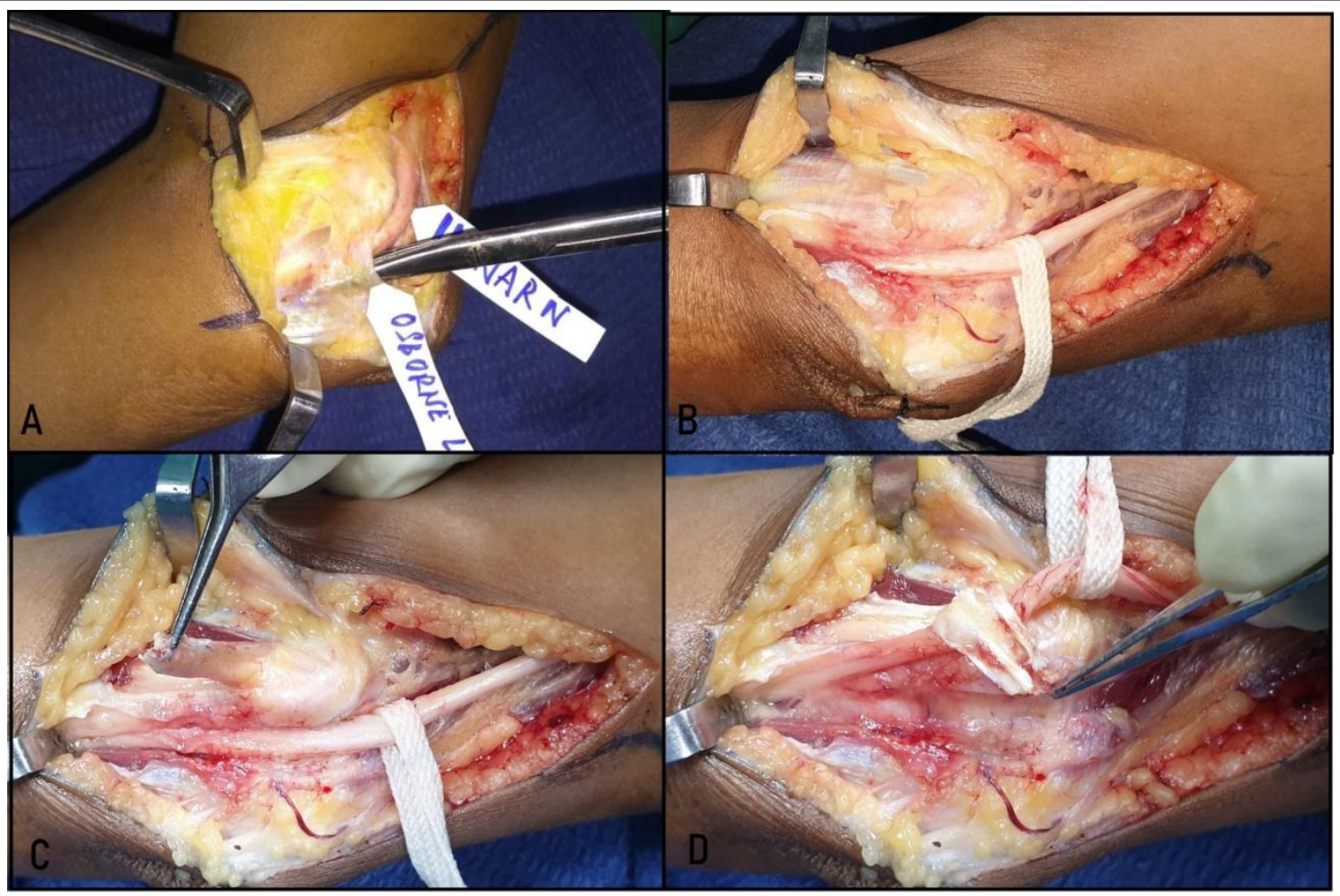

Case-1

A) Ulnar nerve compressed by the osbournes ligament. B) good distal and proximal release of the ulnar nerve has been achieved. C)fascia over the FCU raised. D) anterior transposition of nerve done, and FCU aponeurotic fascia acts as a loop that maintains the nerve in its anterior transposed position.

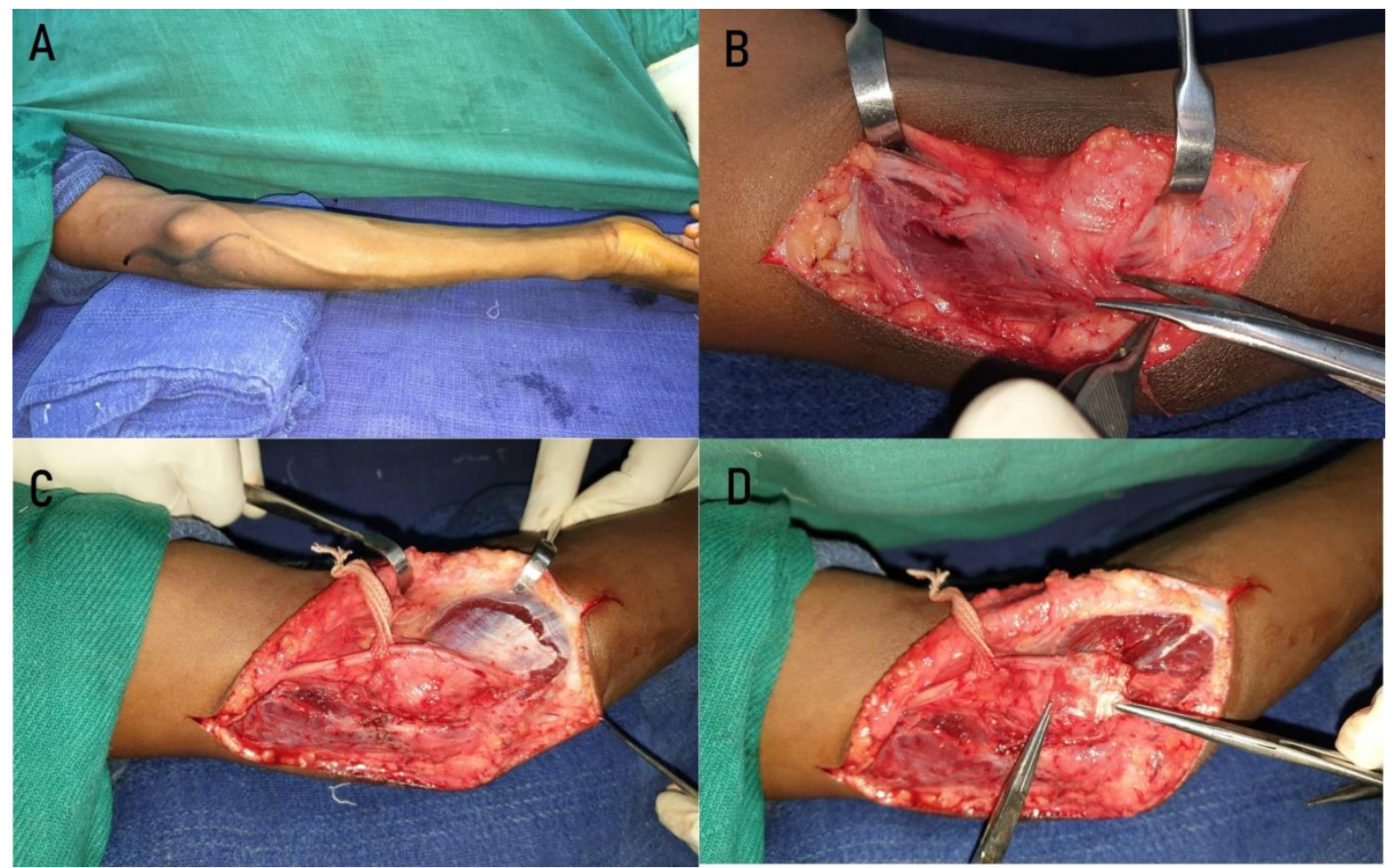

Case-2

A) Incision site marked. B) Arcade of struthers causing compression of ulnar nerve identified. C) Nerve was completely released and FCU fascial flap incision made. D) fascial flap looped around the anteriorly transposed nerve to maintain its position 
Table 1. Modified McGowan classification ${ }^{[10]}$ for preoperative grading of ulnar neuropathy at the elbow

\begin{tabular}{|l|l|c|}
\hline Grade & Description & No. of patients \\
\hline 1 & Patients with subjective sensory symptoms, but without objective & 2 \\
\hline 2A & Patients with good intrinsic strength (4/5), without intrinsic atrophy & 3 \\
\hline 2B & Patients with fair intrinsic strength (3/5), with intrinsic atrophy & 4 \\
\hline 3 & Patients with marked intrinsic atrophy and sensory disturbance & 6 \\
\hline
\end{tabular}

Table 2. Modified Wilson \& Krout criteria ${ }^{[11]}$ for postoperative grading of ulnar neuropathy patients

\begin{tabular}{|c|l|}
\hline GRADE & \multicolumn{1}{c|}{ DESCRIPTION } \\
\hline Excellent & Minimal motor and sensory changes and no tenderness at the incision site \\
\hline Good & Loss of symptoms but a regional sensitivity continued at intervals \\
\hline Fair & $\begin{array}{l}\text { Improved but persistent sensory or motor changes that are milder than the preoperative } \\
\text { status }\end{array}$ \\
\hline Poor & No improvement or worsened condition \\
\hline
\end{tabular}

Table 3. Statistical comparison of the clinical results according to the preoperative scorings of the patients

\begin{tabular}{|l|c|c|c|c|c|}
\hline & 1 & $2 \mathrm{~A}$ & $2 \mathrm{~B}$ & 3 & \\
\hline Excellent & 2 & 2 & 3 & 3 & 1011 \\
\hline Good & & 1 & 1 & 2 & 4 \\
\hline Fair & & & & 1 & 1 \\
\hline Poor & & & & 0 & 0 \\
\hline $\mathrm{p}=0.01, \mathrm{r}=-0.43$ & & & & & \\
\hline
\end{tabular}

Table 4. Statistical comparison of the clinical results according to the symptom duration

\begin{tabular}{|l|c|c|c|c|}
\hline Wilson \& Krout & Duration of & sympt & (months) & Total \\
\hline & $\leq 6$ & $6-12$ & $\geq 12$ & \\
\hline Excellent & 6 & 2 & 2 & 10 \\
\hline Good & & 1 & 3 & 4 \\
\hline Fair & & & 1 & 0 \\
\hline Poor & & & 0 & \\
\hline $\mathrm{p}<0.05$ & & & & \\
\hline
\end{tabular}

\section{Discussion}

There is an increased recognition of cubital tunnel syndrome as a source of upper-extremity sensory and motor symptoms. The treatment for nerve compression is the decompression of the nerve. No consensus exists in the literature regarding the ideal surgical treatment for cubital tunnel syndrome. $^{[7,12-15]}$ Surgical treatment options include simple decompression, decompression with medial epicondylectomy and anterior transposition of the nerve (subcutaneous, intramuscular or submuscular). ${ }^{[1,5,13,15,16]}$

In simple decompression, all tissues constricting the ulnar nerve, mainly the Osborne's ligament, are released; but, the nerve is not separated from its bed. In medial epicondylectomy, in addition to simple decompression, the bone tunnel is expanded by removing a fragment of the bone from the medial epicondyle and thus the compression on the ulnar nerve is further relieved. This procedure may cause more complications than simple decompression. ${ }^{[17]}$

The extrinsic pressure on the nerve can be removed using both of these methods, but the intraneural pressure remains unchanged. The idea behind ulnar nerve transposition is relieving the intraneural pressure which occurs with the traction of the nerve during elbow flexion. ${ }^{[18]}$ The ulnar nerve is subject to traction, friction and pressure with normal elbow motion. Stretching of Osborne's ligament and bulging of medial collateral ligament beneath the nerve causes 
cubital tunnel narrowing during elbow flexion ${ }^{[6,19]}$ During elbow flexion, the cross-sectional oval shape of the cubital tunnel changes to a flattened ellipse. ${ }^{[20]}$ As the elbow is flexed, the cubital tunnel volume decreases by $55 \%$, pressure within the tunnel increases sevenfold and rises to more than twentyfold when contraction of the flexor carpi ulnaris muscle is added. ${ }^{[21]}$ The ulnar nerve moves and stretches during elbow movements. While normal excursion of the ulnar nerve is 16 $\mathrm{mm}$ around the elbow, it increases to $22 \mathrm{~mm}$ with the combined motion of the wrist, fingers, elbow, and shoulder. ${ }^{[24]}$ The ulnar nerve elongates 4.7 $\mathrm{mm}$ with elbow flexion, increasing to $8 \mathrm{~mm}$ with abduction and external rotation of the shoulder.

Anterior transposition of the ulnar nerve, which relaxes the traction and reduces strain on the nerve, will serve to treat the etiology. Simple decompression and decompression with medial epicondylectomy reduces the extrinsic pressure on the nerve, but does not change the traction effect. It is shown that simple decompression does not prevent the traction forces occurring on the nerve with elbow flexion. ${ }^{[26]}$ Moreover, statistically significant instability of the ulnar nerve was found after simple decompression. ${ }^{[27,28]}$

Although a literature review on the surgical treatment of cubital tunnel syndrome does not show any particular procedure to be superior, there usually is a bias on patient selection. The use of the old version of the McGowan's classification system may also be misleading. While patients with mild to moderate symptoms with a short duration usually undergo simple decompression, patients with severe symptoms with a long duration usually undergo anterior transposition, with favorable results in both groups. In our series, the success of the operation in patients who had symptoms of a duration of less than 6 months was statistically higher than the others $(p<0.05)$, which implies that the longer the onset of symptoms, the less the success of surgery (Table 4). Dellon ${ }^{[27]}$ reported that patients with minimal nerve compression obtained excellent results with any surgical procedure. Simple decompression, however, was rarely successful in patients with moderate compression. The efficiency of in situ decompression and partial epicondylectomy were reported to be similar while anterior subcutaneous transposition lacked the efficiency of the other two methods. ${ }^{[7]}$ However, the authors also stated that unequal distribution of the patients according to preoperative grading scale limited the solidity of their results, and anterior subcutaneous transposition proved to have comparable outcomes to partial epicondylectomy in severe cases. In a study by Hahn et al., ${ }^{[13]}$ in which the groups had a similar duration of symptoms, the clinical results of the ulnar nerve decompression with minimal medial epicondylectomy and anterior subcutaneous transposition of the ulnar nerve were similar in spite of the preoperative Dellon's grade at the final follow-up. However, they stated that there were statistical differences between the two groups in terms of the incision length and procedure-related morbidities in favor of the epicondylectomy group.

Mandelli and Baiguini ${ }^{[30]}$ defined an algorithm based on biological properties (nerve morphology and amount of scar tissue around medial epicondyle), preoperative McGowan grade, and clinical parameters for the surgical treatment of cubital tunnel syndrome and attempted to define the most appropriate surgical technique for every patient. They treated 44 patients classified according to this algorithm with modified simple decompression, subcutaneous, and submuscular transposition and obtained successful results. The algorithm seems to be useful, although the number of patients was insufficient to draw a conclusion and the above mentioned disadvantages of simple decompression could not be eliminated even in mild cases.

Subcutaneous anterior transposition of the ulnar nerve is frequently performed as it is a simple procedure with a high success rate and very few complications. Morbidity due to subcutaneous transposition is clearly less when compared to submuscular or intramuscular procedures. ${ }^{[8]}$ In a comparative study of submuscular and 
subcutaneous transposition of the ulnar nerve for cubital tunnel syndrome, sensory and motor recovery for patients with McGowan grades 2 and 3 were similar following submuscular and subcutaneous transposition techniques. ${ }^{[18]}$ Furthermore, no immobilization is necessary after anterior subcutaneous transposition as no muscle or bone intervention is carried out. We did not use postoperative immobilization because early mobilization of the elbow permits early gliding of the ulnar nerve, which prevents the perineural fibrosis that occurs if mobilization is delayed to the second or third postoperative week. ${ }^{[8]}$ It is shown that early mobilization also reduces the return-to-work period. ${ }^{[31]}$

To restrain the nerve in anteriorly transposed position the usual way followed is the subcutaneous tissue being transfixed to the medial epicondyle. This stabilization causes pain and discomfort in some cases due to the sliding of nerve over bony prominence ${ }^{[13]}$. We found a simple way of using FCU aponeurotic fascia to retain the nerve from sliding over the bony prominence.

Complications such as deterioration in ulnar nerve functions and painful neuroma development have been reported after anterior subcutaneous transposition. ${ }^{[13]}$ Cubital tunnel surgery has an average $20 \%$ overall rate of failure, with up to $35 \%$ of patients having residual symptoms at the surgical site after surgery. ${ }^{[32]}$ Failed surgery can be attributed to inadequate decompression, creation of iatrogenic compression, iatrogenic nerve injury, scar formation, kinking of the ulnar nerve or nerve subluxation. Iatrogenic compression can occur at the medial intermuscular septum with anterior transposition as a result of inadequate proximal and distal mobilization of the nerve, as well as kinking of the nerve over an unreleased septum. ${ }^{[33]}$ The medial intermuscular septum should be resected in all patients so that it does not become a proximal site of compression after anterior transposition. ${ }^{[5,33]}$ Cutaneous neuromas are a common cause of continued pain after cubital tunnel surgery. The medial antebrachial cutaneous nerve may be injured or transacted during exposure of the ulnar nerve. Careful dissection at the time of the original surgery is key to preventing nerve injury. The deterioration in ulnar nerve functions is probably due to devascularization of the nerve. ${ }^{[33]}$ We did not observe any of these complications in our patients. None of the patients developed ulnar nerve paralysis, subluxation, or flexion contracture of the elbow. Incisions should be in front of the medial epicondyle in order to protect medial antebrachial cutaneous nerve. ${ }^{[12]}$

We observed that the mid- and long-term results were excellent and good in patients who underwent subcutaneous anterior transposition of the ulnar nerve. No ulnar nerve paralysis developed and none of the patients showed deterioration of the ulnar nerve functions when compared to the preoperative period. Of the 15 patients, 10 had excellent and good results (93\%), 1 had fair (7\%).

\section{Conclusion}

Subcutaneous anterior transposition of the ulnar nerve for the cubital tunnel syndrome is a reliable and easy method with a low complication rate. Using FCU aponeurotic fascia is a simple way of preventing the prolapse of the nerve over the medial epicondyle region.

Conflicts of Interest: No conflicts declared.

\section{References}

1. Asamoto S, Böker DK, Jödicke A. Surgical treatment for ulnar nerve entrapment at the elbow. Neurol Med Chir 2005;45:240-5.

2. Brauer CA, Graham B. The surgical treatment of cubital tunnel syndrome: a decision analysis. J Hand Surg Eur Vol 2007; 32:654-62.

3. Erol B, Tetik C, Sirin E. The mid-term results of minimal medial epicondylectomy and decompression for 
cubital tunnel syndrome. Acta Orthop Traumatol Turc 2004;38:330-36.

4. Keiner D, Gaab MR, Schroeder HW, Oertel J. Comparison of the long-term results of anterior transposition of the ulnar nerve or simple decompression in the treatment of cubital tunnel syndrome - a prospective study. Acta Neurochir 2009; 151:311-6.

5. Palmer BA, Hughes TB. Cubital tunnel syndrome. J Hand Surg Am 2010;35:15363.

6. Feindel W, Stratford J. The role of the cubital tunnel in tardy ulnar palsy. Can $\mathbf{J}$ Surg 1958;1:287-300.

7. Mitsionis GI, Manoudis GN, Paschos NK, Korompilias AV, Beris AE. Comparative study of surgical treatment of ulnar nerve compression at the elbow. J Shoulder Elbow Surg 2010;19:513-9.

8. Dellon AL, Coert JH. Results of the musculofascial lengthening technique for submuscular transposition of the ulnar nerve at the elbow. J Bone Joint Surg Am 2003;85-A:1314-20.

9. Practice parameter for electrodiagnostic studies in ulnar neuropathy at the elbow: summary statement. American Association of Electrodiagnostic Medicine, American Academy of Neurology, American Academy of Physical Medicine and Rehabilitation. Muscle Nerve 1999;22:408-11.

10. Goldberg BJ, Light TR, Blair SJ. Ulnar neuropathy at the elbow: results of medial epicondylectomy. J Hand Surg Am 1989; 14:182-8.

11. Wilson DH, Krout R. Surgery of ulnar neuropathy at the elbow: 16 cases treated by decompression without transposition. Technical note. J Neurosurg 1973;38:7805.

12. Abuelem T, Ehni BL. Minimalist cubital tunnel treatment. Neurosurgery 2009;65:A145-9.
13. Hahn SB, Choi YR, Kang HJ, Kang ES. Decompression of the ulnar nerve and minimal medial epicondylectomy with a small incision for cubital tunnel syndrome: comparison with anterior subcutaneous transposition of the nerve. J Plast Reconstr Aesthet Surg 2010;63:1150-5.

14. Lee SK, Sharma S, Silver BA, Kleinman G, Hausman MR. Submuscular versus subcutaneous anterior ulnar nerve transposition: a rat histologic study. J Hand Surg Am 2009;34: 1811-4.

15. Macadam SA, Gandhi R, Bezuhly M, Lefaivre KA. Simple decompression versus anterior subcutaneous and submuscular transposition of the ulnar nerve for cubital tunnel syndrome: a metaanalysis. J Hand Surg Am 2008;33:1314.e1-12.

16. Cobb TK. Endoscopic cubital tunnel syndrome. J Hand Surg Am 2010;35:16907.

17. Bednar MS, Blair SJ, Light TR. Complications of the treatment of cubital tunnel syndrome. Hand Clin 1994;10:8392.

18. Charles YP, Coulet B, Rouzaud JC, Daures JP, Chammas M. Comparative clinical outcomes of submuscular and subcutaneous transposition of the ulnar nerve for cubital tunnel syndrome. J Hand Surg Am 2009;34:866-74.

19. Vanderpool DW, Chalmers J, Lamb DW, Whiston TB. Peripheral compression lesions of the ulnar nerve. J Bone Joint Surg Br 1968;50:792-803.

20. Apfelberg DB, Larson SJ. Dynamic anatomy of the ulnar nerve at the elbow. Plast Reconstr Surg 1973;51:79-81.

21. Werner CO, Ohlin P, Elmqvist D. Pressures recorded in ulnar neuropathy. Acta Orthop Scand 1985;56:404-6

22. Gelberman RH, Yamaguchi K, Hollstien SB, Winn SS, Heidenreich FP Jr, Bindra 
$\mathrm{RR}$, et al. Changes in interstitial pressure and cross-sectional area of the cubital tunnel and of the ulnar nerve with flexion of the elbow. An experimental study in human cadavera. J Bone Joint Surg Am 1998;80:492- 501.

23. Patel VV, Heidenreich FP Jr, Bindra RR, Yamaguchi K, Gelberman RH. Morphologic changes in the ulnar nerve at the elbow with flexion and extension: a magnetic resonance imaging study with 3 dimensional reconstruction. J Shoulder Elbow Surg 1998;7:368-74.

24. Wilgis EF, Murphy R. The significance of longitudinal excursion in peripheral nerves. Hand Clin 1986;2:761-6.

25. Wright TW, Glowczewskie F Jr, Cowin D, Wheeler DL. Ulnar nerve excursion and strain at the elbow and wrist associated with upper extremity motion. J Hand Surg Am 2001; 26:655-62.

26. Catalano LW 3rd, Barron OA. Anterior subcutaneous transposition of the ulnar nerve. Hand Clin 2007;23:339-44.

27. Dellon AL. Review of treatment results for ulnar nerve entrapment at the elbow. J Hand Surg Am 1989;14:688-700.

28. Robertson C, Saratsiotis J. A review of compressive ulnar neuropathy at the elbow. J Manipulative Physiol Ther 2005; 28:345.

29. McGowan AJ. The results of transposition of the ulnar nerve for traumatic ulnar neuritis. J Bone Joint Surg Br 1950;32B:293-301.

30. Mandelli C, Baiguini M. Ulnar nerve entrapment neuropathy at the elbow: decisional algorithm and surgical considerations. Neurocirugia (Astur) 2009;20:31-8.

31. Weirich SD, Gelberman RH, Best SA, Abrahamsson SO, Furcolo DC, Lins RE. Rehabilitation after subcutaneous transposition of the ulnar nerve: immediate versus delayed mobilization. J Shoulder Elbow Surg 1998;7:244-9.

32. Jackson LC, Hotchkiss RN. Cubital tunnel surgery. Complications and treatment of failures. Hand Clin 1996;12: 449-56.

33. Gellman H. Compression of the ulnar nerve at the elbow: cubital tunnel syndrome. Instr Course Lect 2008;57:18797.

34. Caputo AE, Watson HK. Subcutaneous anterior transposition of the ulnar nerve for failed decompression of cubital tunnel syndrome. J Hand Surg Am 2000;25:54451. 